\title{
Thermal and Mechanical Properties of PVDF/PANI Blends
}

Luiz, Francisco Malmonge ${ }^{\mathrm{a}, *}$, Simone do Carmo Langiano ${ }^{\mathrm{a}}$, João Manoel Marques Cordeiro ${ }^{\text {, }}$

Luiz Henrique Capparelli Mattoso ${ }^{\mathrm{b}}$, José Antonio Malmonge ${ }^{\mathrm{a}}$

a Departamento de Física e Química, Faculdade de Engenharia, Universidade Estadual Paulista - UNESP, Campus Ilha Solteira, CEP 15385-000, Ilha Solteira, SP, Brazil

${ }^{\mathrm{b}}$ Laboratório Nacional de Nanotecnologia para o Agronegócio, Embrapa Instrumentação Agropecuária, CP 741, CEP 13560-970, São Carlos, SP, Brazil

Received: June 11, 2010; Revised: October 19, 2010

\begin{abstract}
Poly(vinylidene fluoride)/polyaniline blends of different composition were synthesized by chemical polymerization of aniline in a mixture of Poly(vinylidene fluoride) and N,N-dimethylformamide and their thermal and mechanical behavior was investigated as a function of the polyaniline doping level and the composition using thermogravimetric analysis, differential scanning calorimetry, dynamic mechanical analysis and tensile tests techniques. The results showed the blend obtained presents a good thermal stability with low weight loss up to $300{ }^{\circ} \mathrm{C}$, assigned to water and solvents evaporation. The glass transition and melting point is not affected by the PANI content in the blend, showing that polymers are no miscible. The films produced present a good sustainability; however the presence of the conducting polymer in the blend increases the tensile strength and the Young modulus, while diminishes the elongation at break, as compared to pure PVDF.
\end{abstract}

Keywords: $P V D F$, polyaniline, PVDF/PANI blend, thermal propriety

\section{Introduction}

Polyaniline (PANI) has been the subject of a good deal of attention in the last three decades mainly on account of its electrical conductivity and unique optical properties. Since the polymer is highly stable at standard conditions, there is an avenue for potential novel applications. However, if the manufacturing process depends on the polymer's melting or solution the production can be hindered, given that PANI is hardly soluble or melted. Because of this, the properties of blends of PANI with commercial polymers were investigated in order to obtain materials that combine the electrical and optical properties of the first with the mechanical properties of the second ${ }^{1-19}$. The methods used to prepare blends and composites of PANI-conventional polymers include solution ${ }^{1-4}$, polymerization in situ $^{5-7,4}$, fusion ${ }^{8-10}$, emulsion ${ }^{11-15}$, and inverse emulsion ${ }^{16-19}$. Poly(vinylidene fluoride) - PVDF is a conventional polymer used as matrix for PANI blends. It has been widely investigated because of its good mechanical properties, chemical stability, high dielectric permittivity and unique pyroelectric and piezoelectric properties ${ }^{20-22}$. It is a semicrystalline material with diverse crystalline forms, with at least five phases that are known as $\alpha, \beta, \gamma, \delta$ and $\varepsilon^{23-26}$. In general the processed material is obtained in the non piezoelectric alpha phase. The behavior of PVDF/PANI blend have been recently investigated through several experimental techniques ${ }^{7,10,27,28}$. From a general point of view, the mechanical and electrical properties of the blend depend on temperature, composition, and preparation route. In our previous work, PVDF/PANI blend were obtained by in situ polymerization of aniline in a PVDF/ $N, N$-dimetylformamide (DMF) solution ${ }^{7}$. The influence of the oxidant/aniline ratio, dopant $p$-toluenesulfonic acid (TSA)/aniline ratio, and PVDF/aniline in the electrical conductivity of the blends were analyzed ${ }^{7}$. The electrical conductivity can achieve values of $1 \mathrm{~S} / \mathrm{cm}$ at a $50 \mathrm{wt}$. (\%) content of PANI in the blend and is stable at temperatures under the $100{ }^{\circ} \mathrm{C}$. As a continuation of our previous work, this study investigates the thermal and mechanical proprieties of those blends as a function of PANI content and PANI doped level, that is important to practical application

\section{Experimental}

\subsection{Synthesis}

The blends were obtained by chemical polymerization of aniline in a solution of PVDF as previously described ${ }^{7}$. In a typical experiment, $1.0 \mathrm{~g}$ was dissolved in $10 \mathrm{~mL}$ of DMF heated at $70{ }^{\circ} \mathrm{C}$ and the mixture cooled at room temperature. The aniline $(0.5 \mathrm{~g})$ was added into this solution under stirring. A $20 \mathrm{~mL}$ of a solution of $1.22 \mathrm{~g}$ ammonium persulfate and $4.28 \mathrm{~g}$ TSA in DMF, and $44.5 \mathrm{~mL}$ of chloroform were slowly added into the mixture. The polymerization reaction was allowed to proceed at room temperature for 2 hours under stirring. After that time, the blend was precipitated by adding distilled water, the solid was filtered and washed with distilled water and aqueous solution of TSA $0.1 \mathrm{M}$ and then dried under dynamic vacuum for 24 hours. In the sequence the blend was maintained heated at $70{ }^{\circ} \mathrm{C}$ for an additional period of 24 hours. Deprotonation was performed keeping the material in a $0.1 \mathrm{M}$ aqueous solution of ammonium hydroxide for 16 hours at room temperature to produce the blend in the dedoped form. The reprotonation was performed by dipping the material into an $\mathrm{HCl}$ aqueous solution of 0.05 and $1.0 \mathrm{M}$, keeping the system under stirring for 30 minutes. After that, the blend was taken out of the acid solution, and dried under dynamic vacuum for 24 hours at room temperature. This procedure produced a blend with 22,4 wt. (\%) of PANI content. Blends of 12 and 30 wt. (\%) were also obtained following the same procedure using different proportions of aniline, oxidant etc, as described in previous work. 
PANI content in the blends were calculated on the basis of elemental analysis. Thick films $(\approx 200 \mu \mathrm{m})$ were obtained by pressing the material (powder form) under a pressure of $30 \mathrm{MPa}$ at $180^{\circ} \mathrm{C}$. Doped (PANI-HCl) and dedoped (PANI-EB) were obtained using the same procedure in the absence of PVDF.

\subsection{Measurements}

Thermogravimetric Analysis (TGA) was performed in a Netzch STA 409 equipment within a temperature range of 25 to $700{ }^{\circ} \mathrm{C}$ at a heating rate of $10^{\circ} \mathrm{C} / \mathrm{min}$ and $\mathrm{N}_{2}$ atmosphere. Differential Scanning Calorimetry (DSC) analysis were performed in a TA Instruments MDSC 2920 equipment within a temperature range of 0 to $300{ }^{\circ} \mathrm{C}$ at a heating rate of $10{ }^{\circ} \mathrm{C} / \mathrm{min}$ in $\mathrm{N}_{2}$ atmosphere. The Dynamic Mechanical Analysis (DMA) was performed using a TA Instruments DMA Q800 V7.0 analyzer. The measurements were performed from $-80{ }^{\circ} \mathrm{C}$ to $80{ }^{\circ} \mathrm{C}$ at a heating rate of $2{ }^{\circ} \mathrm{C} /$ min under $\mathrm{N}_{2}$ and a constant frequency of $1.0 \mathrm{~Hz}$. The stress-strain tests were conducted using an EMIC DL 300 equipment at room temperature and a deformation rate of $13 \mathrm{~mm} / \mathrm{min}$ using a cell of $100 \mathrm{~N}$ and initial grips separation of $23.4 \mathrm{~mm}$. The samples were strips cut from a thin sheet following the specifications of the ASTM D882-95a standard. Five specimens were tested for each sample composition.

\section{Results and Discussion}

Thermogravimetric analysis provides useful information on the thermal stability of materials. Figure 1 shows the thermogravimetric behavior of the PANI, PVDF and the blends investigated in this work. The onset degradation temperature of the polymer chain for pristine $\mathrm{PVDF}^{29,30}$ is around $400{ }^{\circ} \mathrm{C}$. On the other hand, redoped PANI (PANI-HCl) presents considerable weight loss at much lower temperatures than for PVDF. The weight loss below $150^{\circ} \mathrm{C}$ has been assigned to water $\operatorname{loss}^{31,32}$, and at a higher temperature $\left(>150{ }^{\circ} \mathrm{C}\right)$, due to the loss of bonded water and dopant $t^{32-37}$. Above $420^{\circ} \mathrm{C}$, the weight loss is associated with the degradation of the polymer chain structure, in agreement with the literature ${ }^{38,39}$. The analysis shows that the blends in the compositions studied have a stability that is closest to the stability of PVDF, with a intensive weight loss onset at around $400{ }^{\circ} \mathrm{C}$, which is associated to the weight losses for PVDF

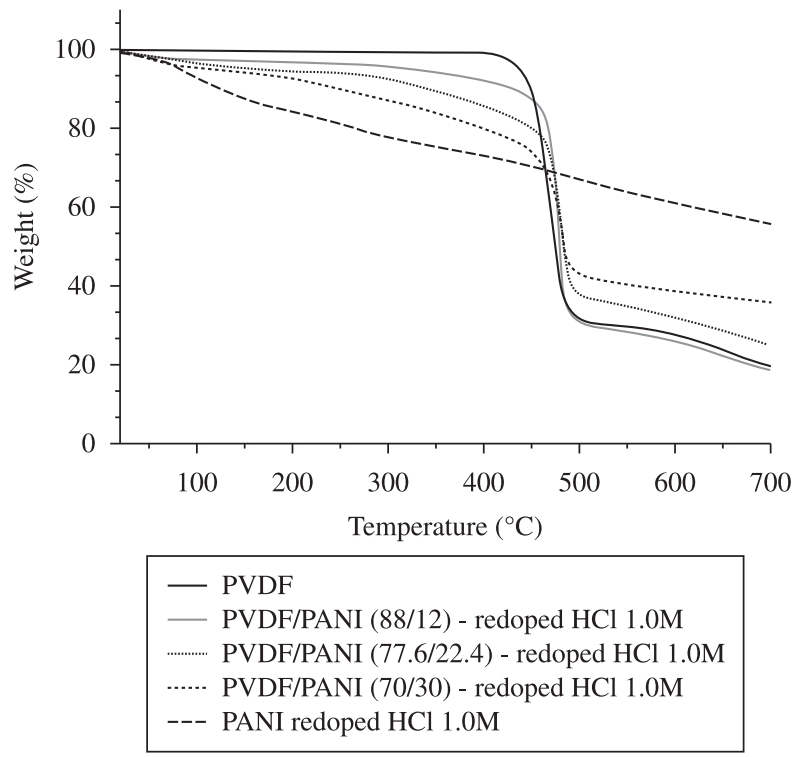

Figure 1. Thermogravimetric analysis of: PVDF, PANI and PVDF/PANI blend $(12,22.4$ and $30 \mathrm{wt}$. (\%) PANI). The PANI and blends are redoped with $\mathrm{HCl} 1,0 \mathrm{M}$. and PANI as discussed above. The thermogravimetric analysis for the PVDF/PANI blend (22.4 wt. (\%) PANI), dedoped and redoped with $\mathrm{HCl} 0.05 \mathrm{M}$ and $1.00 \mathrm{M}$, is shown in Figure 2. A small weight loss is observed at a temperature lower than $120{ }^{\circ} \mathrm{C}$ in the redoped blends, assigned to water loss, which was not noticed for the dedoped blend. The water absorption is higher for the doped polyaniline due to ionic salvation ${ }^{40}$. Moreover, the redoped blends show a more significant weight loss for temperatures between 300 and $450{ }^{\circ} \mathrm{C}$, than the dedoped one. A similar behavior is observed in the blends containing 12 and 30 wt. (\%) of PANI (Figures 3 and 4, respectively). The results show that the loss of dopant in the blends is related to the acid concentration used for doping. This result is in agreement with the literature ${ }^{41}$.

Figure 5 shows the DSC thermograms of the dedoped PANI-EB (emeraldine base), PANI redoped with $\mathrm{HCl}$ 1.0M (PANI-HCl) and PVDF. The PANI thermograms show a broad endothermic peak at around $110{ }^{\circ} \mathrm{C}$, assigned to water loss, which is greater to the redoped PANI. This finding is in agreement with the TGA analysis, discussed above. The graphics also show an exothermic transition at around $270{ }^{\circ} \mathrm{C}$ for the PANI-EB, which has been assigned to cross linking ${ }^{36}$. This transition is noticed in a smaller extension for the PANI-HCl sample. Scherr et al. ${ }^{42}$ suggested the crosslinking reaction results from a coupling of two neighboring $-\mathrm{N}=\mathrm{Q}=\mathrm{N}-$ groups to give two - NH-B-NH- groups thorough a link of the $\mathrm{N}$ with its neighboring quinoid ring. Here $\mathrm{Q}$ and $\mathrm{B}$ represent the quinoid and benzenoid ring, respectively. In the redoped PANI, the amount of quinoid ring is smaller and consequently the exothermic transition is less emphasized. The endothermic peak observed around $175^{\circ} \mathrm{C}$ for

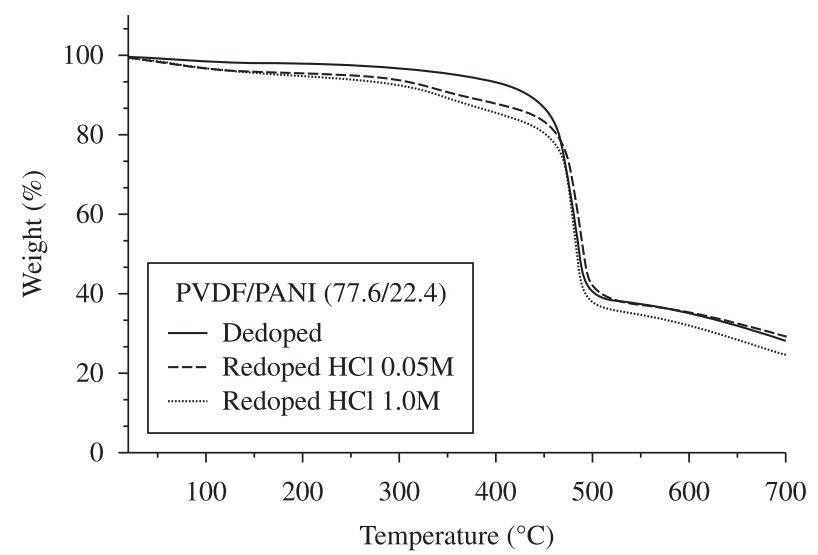

Figure 2. Thermogravimetric analysis of PVDF/PANI blends (22,4 wt. (\%) PANI) dedoped and redoped with $\mathrm{HCl} \mathrm{0,05} \mathrm{M}$ and 1,0 M.

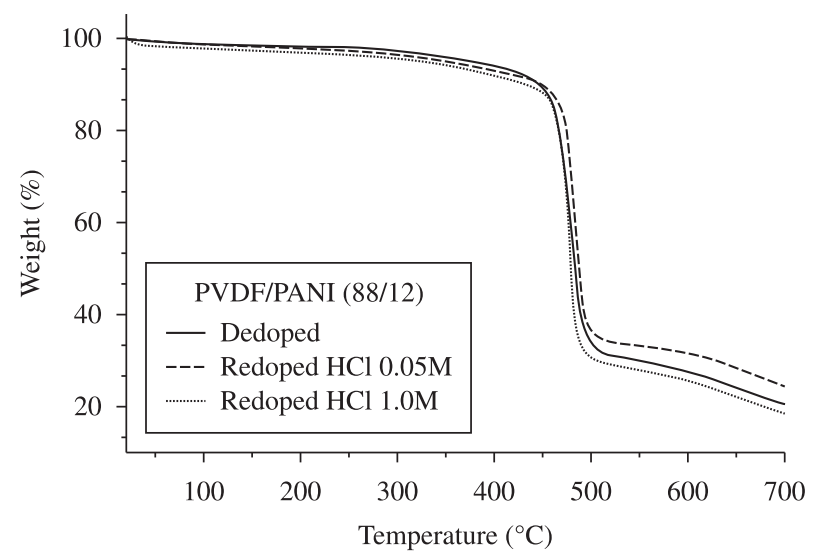

Figure 3. Thermogravimetric analysis of PVDF/PANI blends (12 wt. (\%) PANI) dedoped and redoped with $\mathrm{HCl} 0,05 \mathrm{M}$ and 1,0 M. 
PVDF is assigned to the melting of its crystalline regions ${ }^{37}$. In Figure 6 thermograms of PVDF, PANI-EB, and PVDF/PANI blends with 12, 22.4 and $30 \mathrm{wt}$. (\%) of dedoped PANI are shown. The exothermic peak at $\approx 250{ }^{\circ} \mathrm{C}$ associated with crosslinking ${ }^{43}$ for dedoped blends can be observed, except for the 12 wt. (\%) PANI blend. That must be a consequence of the low percentage of PANI in the sample that compromises the observation of such transition. It is also observed that the melting point of PVDF keeps constant, regardless of the blend composition, hence a strong indication that the polymers are not miscible. On the other hand, the intensity of this peak is proportional to the percentage of PVDF in the blend, as expected, since the peak is related to the melting heat. Figure 7 shows the DSC thermograms of the PVDF, PANI-HCl and the PVDF/PANI blends with 12, 22.4, and 30 wt. (\%) of PANI redoped with $\mathrm{HCl} 1.0 \mathrm{M}$. The results are similar to those discussed above, with the exception that the degradation peaks are less evident than for the dedoped ones.

Storage modulus (E') and loss factor $\left(\tan \delta=E^{\prime \prime} / E^{\prime}\right)$ as a function of the temperature for the PVDF are shown in Figure 8. The curve of $\tan \delta$ has a peak at around $-40{ }^{\circ} \mathrm{C}$ that was assigned to the glass transition temperature ${ }^{44}$. This is associated with a strong decrease of the storage modulus in that region. The DMA results obtained for the dedoped PVDF/PANI blends with 12, 22.4 and 30 wt. (\%) of PANI can be seen in Figure 9. The presence of PANI in the blend did not change the glass transition temperature, indicating that the

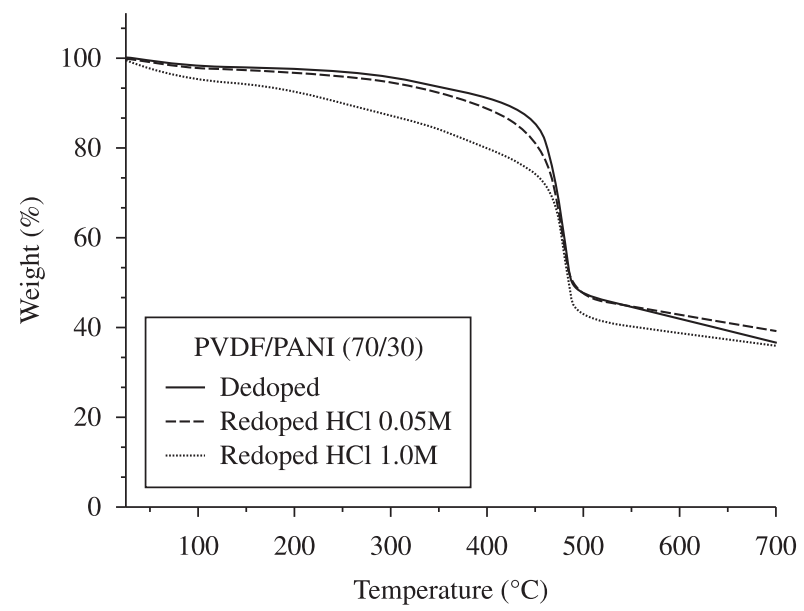

Figure 4. Thermogravimetric analysis of PVDF/PANI blends (30 wt. (\%) PANI) dedoped and redoped with $\mathrm{HCl}$ 0,05 M and 1,0 M.

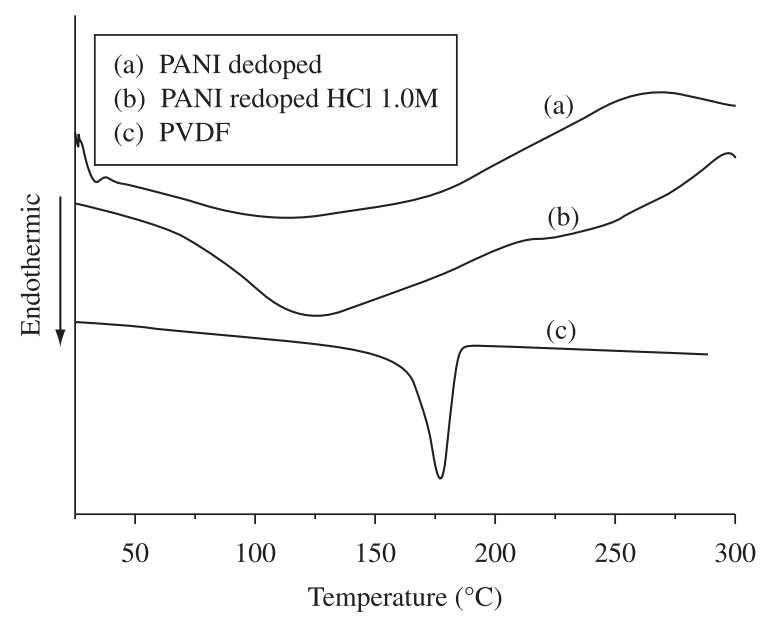

Figure 5. DSC thermograms of: a) PANI-EB; b) PANI-HCl; and c) PVDF. blend components are immiscible, in agreement with the results obtained by DSC.

Figure 10 shows the stress-strain curves for pure PVDF and for the PVDF/PANI blends containing 12 and $22.4 \mathrm{wt}$. (\%) of dedoped PANI. It is noticed that the elongation at break decreases as the content of PANI in the blend increases. The tensile increases from $40 \mathrm{MPa}$ for pure PVDF, to 50 and $55 \mathrm{MPa}$, respectively, for blends with 12 and 22.4 wt. (\%) of PANI and the Young modulus changed from 1.2 GPa for PVDF to 1.5 GPa for blends with 12 and $22.4 \mathrm{wt}$. (\%) of PANI (values obtained from the slope of the curves in Figure 8 in the

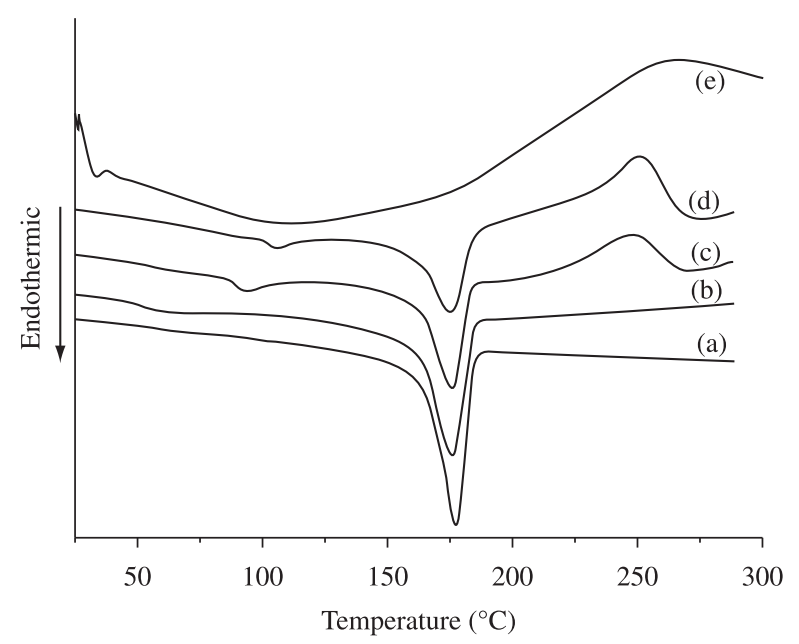
(a) PVDF
(b) PVDF/PANI (88/12) - dedoped
(c) PVDF/PANI (77.6/22.4) - dedoped
(d) PVDF/PANI (70/30) - dedoped
(e) PANI dedoped

Figure 6. DSC thermograms of: a) PVDF; b) PVDF/PANI (12 wt. (\%) PANI); c) PVDF/PANI (22,4 wt. (\%) PANI); d) PVDF/PANI (30 wt. (\%) PANI); and e) PANI. The PANI and blends are dedoped.

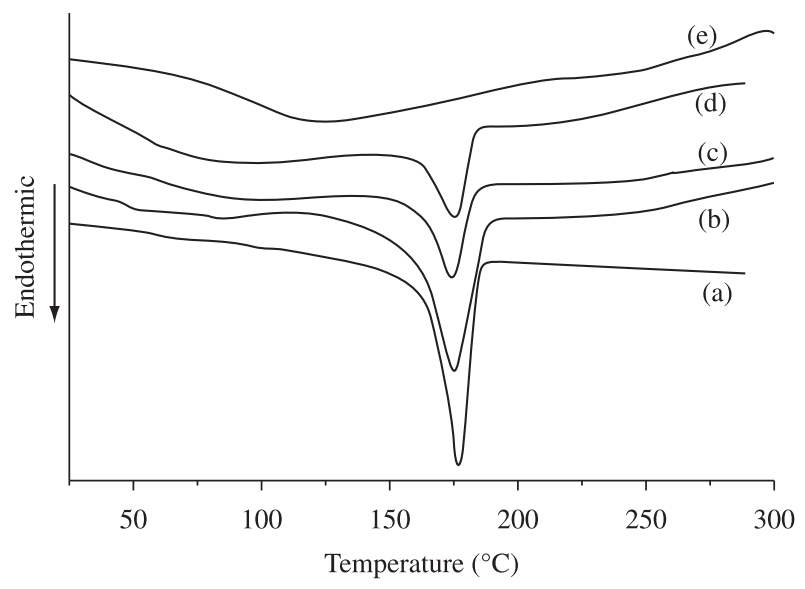
(a) PVDF
(b) PVDF/PANI (88/12) - dedoped
(c) PVDF/PANI (77.6/22.4) - dedoped
(d) PVDF/PANI (70/30) - dedoped
(e) PANI dedoped

Figure 7. DSC thermograms of: a) PVDF; b) PVDF/PANI (12 wt. (\%) PANI); c) PVDF/PANI (22,4 wt. (\%) PANI); d) PVDF/PANI (30 wt. (\%) PANI); and e) PANI. The PANI and blends are redoped with HCl-1.0 M. 


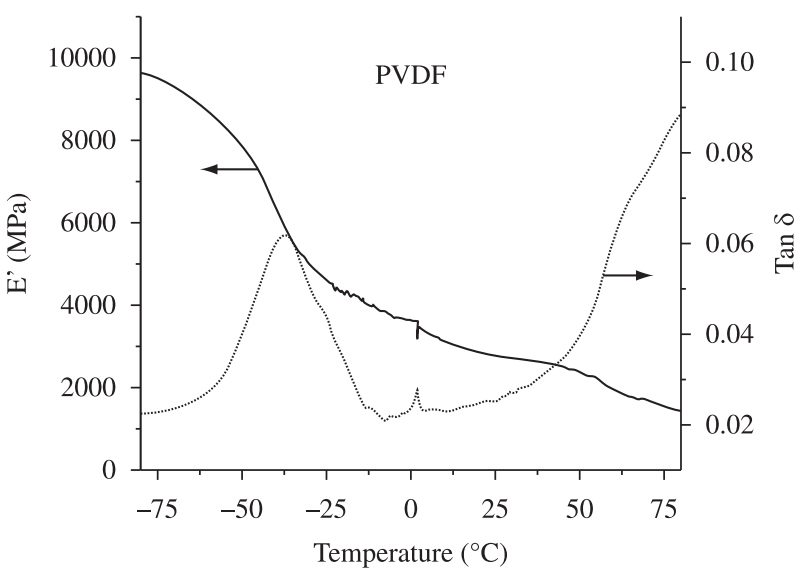

Figure 8. The DMA measured storage modulus and $\tan \delta$ of the PVDF.

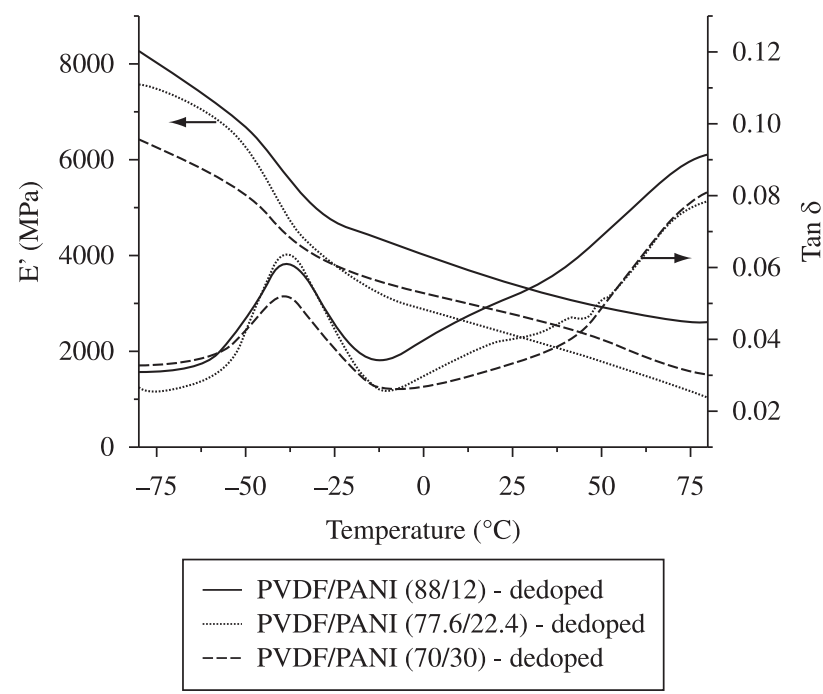

Figure 9. The DMA measured storage modulus and $\tan \delta$ of the PVDF/ PANI (12 wt. (\%) PANI), PVDF/PANI (22,4 wt. (\%) PANI) and PVDF/PANI (30 wt. (\%) PANI). The blends are dedoped.

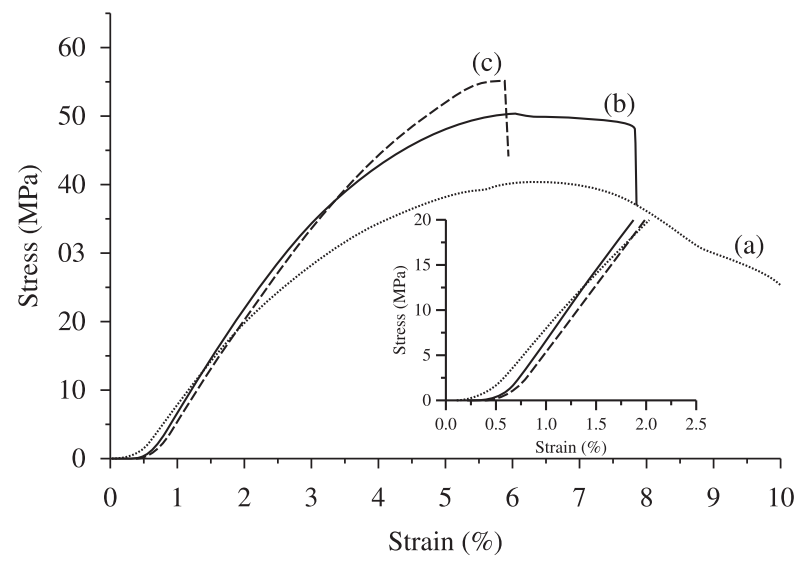

(a) PVDF

(b) PVDF/PANI (88/12) - dedoped

(c) PVDF/PANI (77.6/22.4) - dedoped

Figure 10. Stress-strain curves of: a) PVDF; b) PVDF/PANI (12 wt. (\%) PANI); and c) PVDF/PANI (22,4 wt. (\%) PANI). The blends were dedoped. elastic region). Additionally, the elastic region also becomes larger with the increase of the PANI percentage in the blend (changing from 2.5 to $4 \%$ ), although the value of $\mathrm{E}$ does not change. This suggests PANI is reinforcing the PVDF matrix, constraining the PVDF chain movements and increasing the tensile strength of the blend to a higher stiffness associated with the PANI backbone. In order to investigate the effect of doping on the mechanical properties of the blends, stress-strain tests were performed for blends with 12 and $22.4 \mathrm{wt}$. (\%) of PANI redoped with 0.05 and $1.0 \mathrm{M} \mathrm{HCl}$. The results obtained are presented in Figures 11 and 12. As a general behavior, the acid dopant renders the PVDF/PANI more brittle, as the acid used for redoping is more concentrated. The elastic component is not significantly affected by the acid concentration (insets of Figures 11 and 12). It

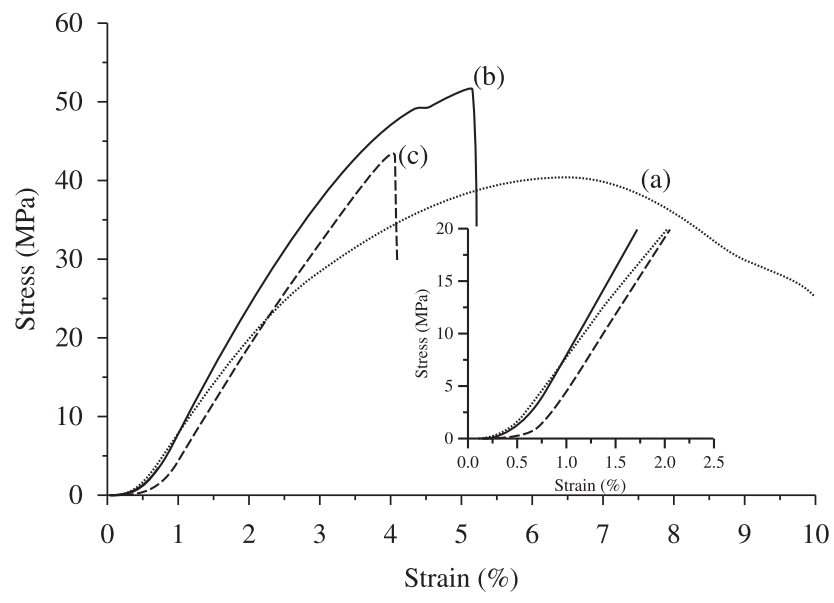

(a) PVDF

(b) PVDF/PANI (88/12) red. $\mathrm{HCl} 0.05 \mathrm{M}$

(c) PVDF/PANI (77.6/22.4) red. $\mathrm{HCl} 0.05 \mathrm{M}$

Figure 11. Stress-strain curves of: a) PVDF; b) PVDF/PANI (12 wt. (\%) PANI); and c) PVDF/PANI (22,4 wt. (\%) PANI). The blends were redoped with $\mathrm{HC} 0,05 \mathrm{M}$.

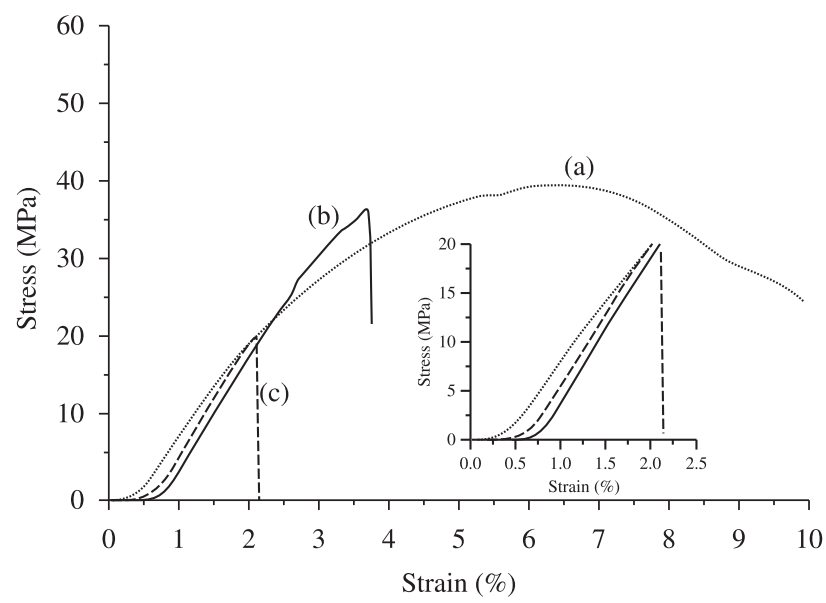

(a) PVDF

(b) PVDF/PANI (88/12) red. $\mathrm{HCl} 1.0 \mathrm{M}$

(c) PVDF/PANI (77.6/22.4) red. $\mathrm{HCl} 1.0 \mathrm{M}$

Figure 12. Stress-strain curves of: a) PVDF; b) PVDF/PANI (12 wt. (\%) PANI); and c) PVDF/PANI (22,4 wt. (\%) PANI). The blends were redoped with $\mathrm{HCl}$ 1,0 M. 
is well known that doped PANI becomes more crystalline at higher doping levels ${ }^{16,45}$, diminishing the elongation at break when compared with the undoped one.

\section{Conclusions}

In conclusion, our results of the blend of PVDF/PANI showed better thermal stability than the conductive polymer alone. The melting point of PVDF crystallites and its glass transition is not affected by the PANI component, showing that the polymers are not miscible. The presence of PANI in the blend increases the tensile strength and the Young modulus, when compared to pure PVDF. On the other hand, the blend becomes more brittle, thus increasing the PANI doped level.

\section{Acknowledgements}

The authors are grateful for the financial support given by Fundação de Amparo à Pesquisa do Estado de São Paulo (FAPESP) and Coordenação de Aperfeiçoamento de Pessoal de Nível Superior (CAPES).

\section{References}

1. Yang CY, Cao Y, Smith P and Heeger AJ. Morphology of conductive solution-processed blends of polyaniline and poly(methyl methacrylate). Synthetic Metals. 1993; 53:293-391.

2. Wang P, Tan KL, Kang ET and Neoh KG. Preparation and characterization of semi-conductive poly(vinylidene fluoride)/polyaniline blends an membranes. Applied Surfarce Science. 2002; 193:36-45.

3. Malmonge LF and Mattoso LHC. Electroactive blends of poly(vinylidene fluoride) and polyaniline derivatives. Polymer. 1995; 36:245-249.

4. Barra GMO, Matins RR, Kafer KA, Paniago R, Vasques CT and Pires ATN. Thermoplastic elastomer/polyaniline blends: evaluation of mechanical and electromechanical properties. Polymer Testing. 2008; 27:886-892.

5. Schettini ARA, Peres RCD and Soares BG. Synthesis of polyaniline/ camphor sulfonic acid in formic acid medium and their blends with polyamide-6 by in situ polymerization. Synthetic Metals. 2009; 159:1491-1495.

6. Rubinger CPL, Faez R, Costa C, Martins CR and Rubinger RM. Dielectric properties of PANI/PSS blends obtained by in situ polymerization technique. Polymer Bulletin. 2008; 60:379-386.

7. Malmonge LF, Lopes GA, Langiano SC, Malmonge JA, Cordeiro JMM and Mattoso LHC. A new route to obtain PVDF/PANI conducting blends. European Polymer Journal. 2006; 42:3108-3113.

8. Faez R, Gazotti WA and De Paoli MA. An elastomeric conductor based on polyaniline prepared by mechanical mixing. Polymer. 1999; 40:5497-5503.

9. Cruz-Estrada RH and Folkes MJ. In-situ production of electrically conductive fibres in polyaniline-SBS blends. Journal of Materials Science. 2000; 35:5065-5069.

10. Ray S, Easteal AJ, Cooney RP and Edmonds NR. Structure and properties of melt-processed PVDF/PMMA/polyaniline blends. Material Chemistry and Physics. 2009; 113:829-838.

11. Ruckenstein E and Yang S. An Emulsion pathway to electrically conductive polyaniline-polyestirene composites. Synthetic Metals. 2003; 53:283-292.

12. Yang S and Ruckenstein E. Processable conductive composites of polyaniline/poly(alkilmethacrylate) prepared via an emulsion method. Synthetic Metals. 1993; 59:1-12.

13. Jeon BH, Kim S, Choi MH and Chung IJ. Synthesis and characterization of polyaniline-carbonate composites prepared by an emulsion polymerization. Synthetic Metals. 1999; 104:95-100.
14. Rao PS, Subrahmanya S and Sathyanarayana DN. Polyanilinepolycarbonate blends synthesized by two emulsion pathway. Synthetic Metals. 2004; 143:323-330.

15. Xie HQ, Ma YM and Guo JS. Conductive polyaniline-SBS Composites from in situ emulsion polymerization. Polymer. 1998; 40:261-265.

16. Ruckenstein E and Sun Y. Polyaniline-containing electrical conductive composite prepared by two inverted emulsion pathways. Synthetic Metals. 1995; 74:107-113.

17. Rao PS, Subrahmanya S and Sathyanarayana DN. Inverse emulsion polymerization: a new route for the synthesis of conducting polyaniline. Synthetic Metals. 2002; 128:311-316.

18. Rao PS and Sathyanarayana DN. Inverted emulsion cast electrically conducting polyaniline-polystyrene blends. Applied of Polymer Science. 2002; 86:1163-1171.

19. Rao PS, Subrahmanya S and Sathyanarayana DN. Synthesis by inverse emulsion pathway and characterization of polyaniline-poly(ethylene-covinyl acetate) blends. Synthetic Metals. 2003; 139:397-404.

20. Su H, Strachan A and Goddard WA. Density functional theory and molecular dynamics studies of the energetics and kinetics of electroactive polymers: PVDF and P(VDF-TrFE). Physical Review B. 2004; 70(6):64101.

21. Nakhmanson SM, Nardelli MB and Bernholc J. Ab Initio Studies of Polarization and Piezoelectricity in Vinylidene Fluoride and BN-Based Polymers. Physical Review Letter. 2004; 92(11):115504.

22. Yee WA, Kotaki M, Liu Y and Lu XH. Morphology, polymorphism behavior and molecular orientation of electrospun poly(vinylidene fluoride) fibers. Polymer. 2007; 48:512-521.

23. Gao Q and Scheinbein JI. Dipolar Intermolecular Interactions, Structural Development, and Electromechanical Properties in Ferroelectric Polymer Blends of Nylon-11 and Poly(vinylidene fluoride). Macromolecules. 2000; 33:7564-7572.

24. Benz M and Euler WB. Determination of the Crystalline Phases of Poly(vinylidene fluoride) Under Different Preparation Conditions Using Differential Scanning Calorimetry and Infrared Spectroscopy. Journal of Applied Polymer Science. 2003; 89:1093-1100.

25. Ramer NJ, Marrone T and Stiso KA. Structure and vibrational frequency determination for a-poly(vinylidene fluoride) using density-functional theory. Polymer. 2006; 47:7160-7165.

26. Mohammadi B, Yousefi AA and Bellah SM. Effect of tensile strain rate and elongation on crystalline structure and piezoelectric properties of PVDF thin films. Polymer Testing. 2007; 26:42-50.

27. Huang $\mathrm{C}$ and Zhang QM. Fully functionalized high-dielectric-constant nanophase polymers with high electromechanical response. Advanced Materials. 2005; 17:1153-1158.

28. Bobnar V, Levistk A, Huang C and Zhang QM. Enhanced dielectric response in all-organic polyaniline - poly(vinylidene fluoride-trifluoro ethylenechlorotrifluoroethylene) composite. Journal of Non-Crystalline Solids. 2007; 353:205-209.

29. Lovinger AJ. Poly(vinylidene fluoride) In: Basset DC, editor. Development in Crystalline Polymers. London: Applied Science Publisher; 1982.

30. Zulfiqar S, Zulfiqar M and Munir A. Study of the thermal-degradation of polychlorotrifluoroethylene, poly(vinylidene fluoride) and copolymers of chlorotrifluoroethylene and vinylidene fluoride. Polymer Degradation and Stability. 1994; 43(3):423-430.

31. Lei X, Guo X, Zhang L, Wang Y and Su ZJ. Synthesis and properties of novel conducting polyaniline copolymers. Applied of Polymer Science. 2007; 103(1):140-147.

32. Sinha M, Bhadra S and Khastgir D. Effect of Dopant Type on the Properties of Polyaniline. Journal of Applied Polymer Science. 2009; 112:3135-3140.

33. Morgan H, Foot PJS and Brooks NW. Thes effects of composition and processing variables on the properties of thermoplastic polyaniline blends and composites. Journal of Materials Science. 2001; 36:5369-5377. 
34. Palaniappan S and Narayana BH. Conducting polyaniline saltsthermogravimetric and differential thermal analysis. Thermochimica Acta. 1994; 237(1):91-97.

35. Palaniappan $\mathrm{S}$ and Narayana BH. Temperature effect on conducting polyaniline salts-thermal and spectral studies. Journal of Polymer Science Part A-Polymer Chemistry. 1994; 32(13):2431-2436.

36. Pandey SS, Gerard M, Sharma AL and Malhotra BD. Thermal analysis of chemically synthesized polyemeraldine base. Journal of Appied Polymer Science. 2000; 75(1):149-155.

37. Malmonge LF and Mattoso LHC. Thermal analysis of conductive blends of PVDF and poly(o-methoxyaniline). Polymer. 2000; 41:8387-8391.

38. Conklin JA, Huang SC, Huang SM, Wen T and Kaner RB. Thermal Properties of Polyaniline and Poly( aniline-co-o-ethylaniline). Macromolecules. 1995; 28:6522-6527.

39. Li W and Wan M. Stability of Polyaniline Synthesized by a DopingDedoping-Redoping Method. Journal of Applied Polymer Science. 1999; 71:615-621.
40. Ostwal MM, Sahimi M and Tsotsis TT. Water harvesting using a conducting polymer: A study by molecular dynamics simulation. Physical Review E. 2009; 79:061801(1-16).

41. Ostwal MM, Pellegrino J, Norris I, Tsotsis TT, Sahimi M and Mattes BR. Water Sorption of Acid-Doped Polyaniline Solid Fibers: Equilibrium and Kinetic Response. Industrial of Engineering Chemistry Research. 2005; 4:7860-7867.

42. Scherr EM, MacDiarmid AG, Manohar SK, Masters JG, Sun Y, Tang X et al. Polyanilines: Oriented Films and Fibers. Synthetic Metals. 1991; 41:735-738.

43. Chen CH. Thermal and Morphological Studies of Chemically Prepared Emeraldine-Base-Form Polyaniline Powder. Journal of Applied Polymer Science. 2003; 89:2142-2148.

44. Liu Z, Maréchal P and Jérôme R. DMA. and DSC investigations of the transition of poly(vinylidene fluoride). Polymer. 1997; 38(19):4925-4929.

45. Li W and Wan M. Porous polyaniline films with high conductivity. Synthetic Metals. 1998; 92:121-126. 